\title{
In vitro antibacterial activity of Terminalia chebula leaf gall extracts against some human pathogenic strains
}

\author{
*BE Ravi Shankara1,2,3, YL Ramachandra², S Sundara Rajan³, J Preetham4, PS Sujan Ganapathy \\ ${ }^{1}$ Department of Chemistry, SBMJC, Jain University, JC Road-560002, Karnataka, India \\ ${ }^{2}$ P.G. Department of Studies and Research in Biotechnology, Kuvempu University, Shankaraghatta-577451, Karnataka, India \\ ${ }^{3}$ Research Unit in Vrkshayurveda, Jain University, Chamrajpet-560019, Karnataka, India \\ ${ }^{4}$ Department of Life Sciences, Dayananda Sagar Educational Institutions, Kumaraswamy Layout-560078, Karnataka, India
}

\begin{abstract}
The leaf galls of Terminalia chebula is used widely as Karkatasringi in south Indian markets. Karkatashringi is an important crude drug employed in various indigenous systems of medicine against several diseases and the drug has diverse medicinal properties. The present study was carried out to understand the antimicrobial activity of various extracts. The antibacterial activity of T. chebula (leaf gall) was evaluated against ten bacterial strains including Grampositive and Gram-negative bacteria using the agar-well diffusion method. Among the two extracts tested, the ethanol extract presented the best results against all the bacteria while aqueous extract showed moderate inhibition of the microbial growth. Each extract is unique against different microorganisms; Staphylococcus aureus was more susceptible to both extract among the tested organisms, whereas Serratia marcescens and Proteus mirabilis were less susceptible for ethanol and aqueous extract respectively. The inhibitory effect of the extracts was compared with standard antibiotic Ciprofloxacin.
\end{abstract}

Key Words: Terminalia chebula, leaf gall, antibacterial activity, agar well diffusion method.

\section{INTRODUCTION}

In view of increasing resistance to existing antimicrobial agents, herbal drugs are being looked as very important source for discovery of new agents for treating various ailments related to bacterial infections (Roopashree et al., 2008). Terminalia chebula Retz. (Combretaceae), Commonly known as black myrobalan and haritaki, is an important plant used in indigenous systems of medicine as remedy for fever, cough, diarrhea, gastroenteritis, skin diseases, candidiasis, urinary tract infection and wound infections (Kirtikar and Basu, 1987; Anonymous, 1999). T. chebula has been reported to possess anti-oxidant (Cheng et al., 2003), anti-diabetic (Sabu and Kuttan, 2002), anti-cancer (Saleem et al., 2002), anti-mutagenic (Kaur et al., 2002), anti-viral (Ahn et al., 2002), anti-bacterial (Kim et al., 2006; Chat-

\footnotetext{
*Corresponding Author:

BE Ravi Shankara, Associate Professor

Department of Chemistry, SBMJC

Jain University, JC Road

Karnataka, India-560002

E-mail: mr_ravish@rediffmail

Contact No.: +919886414024
}

topadhyay et al., 2007, Bag et al., 2009) and radioprotective activity (Gandhi and Nayar, 2005).

The leaf galls of T. chebula are used as a substitute for Karkatshringi, which is widely used in Ayurvedic and other traditional systems of medication. Karkatshringi is the main component of Karkatadi churna, Balabhadra churna, Sringadi churna which are used in treatment of asthma, tuberculosis, indigestion, heart diseases, fevers and liver disorders. Similarly, in Siddha system of medication, they are used in the preparation of Karisalai lehyam, Venpocesunai nei, Gana thailum for treating diseases like cough, bronchial asthma, diarrhea, dysentery (Shantha et al., 1991).

The present study was undertaken to investigate the antibacterial activity of $T$. chebula leaf gall extract against ten human pathogens (Pseudomonas aeruginosa, Klebsiella pneumonia, Salmonella typhi, Escherichia coli, Serratia marcescens, Proteus mirabilis, Staphylococcus aureus, Staphylococcus citreus, Bacillus polymyxa, Bacillus cereus). 


\section{MATERIALS AND METHODS}

\section{Plant Material}

T. chebula leaf galls were purchased from a local market of Bangalore, Karnataka (Southern India) in May 2010 and authenticated by Dr. S. Sundara Rajan and voucher specimen (JU-RUV-52) were deposited at the Research Unit in Vrkshayurveda, Jain University, Bangalore.

\section{Preparation of Extract}

One hundred gram of pulverized plant material were taken in five hundred capacity thimble of Soxhlet apparatus and refluxed with ethanol and water separately until all soluble compounds had been extracted. Extraction was considered to be complete when the filtrate had a faint colour. The extracts were evaporated to dryness under reduced pressure using a Rotavapor (Buchi Flawil, Switzerland). A portion of the residue was used for the antibacterial assay.

\section{Bacterial Culture}

The bacterial strains used in this study were clinical isolates. The isolates were identified by a standard method (Cowan et al., 1993). The organisms were maintained on nutrient agar slope at $4^{\circ} \mathrm{C}$ and subcultured into nutrient broth by a picking-off technique (Aneja, 2003) for 24 hrs before use.

\section{Bacterial Susceptibility Testing}

In vitro antibacterial activity of the crude extracts was studied against Gram-negative and Grampositive bacteria by the agar well diffusion method (Nair et al., 2005). Nutrient agar (Hi Media, India) was used as the bacteriological medium. The extracts were dissolved in $10 \%$ aqueous dimethylsulfoxide (DMSO) to a final concentration of $100 \mathrm{mg} / \mathrm{ml}$. Pure DMSO was taken as the negative control and $50 \mathrm{mg} / \mathrm{ml}$ Ciprofloxacin as the positive control. $100 \mu \mathrm{l}$ of inoculum was aseptically introduced on to the surface of sterile agar plates and sterilized cotton swabs were used for even distribution of the inoculum. Wells were prepared in the agar plates using a sterile cork borer of $6.0 \mathrm{~mm}$ diameter. $100 \mu \mathrm{l}$ of test and control compound was introduced in the well. The same procedure was used for all the strains. The plates were incubated aerobically at $35^{\circ} \mathrm{C}$ and examined after 24 hours (Ali-Shtayeh et al., 1998; Colins et al., 1989). The diameter of the zone of inhibition produced by each
Table 1: Antibacterial activity of Terminalia chebula leaf gall extract against bacterial strains.

\begin{tabular}{llll}
\hline & $\begin{array}{l}\text { Ethanol } \\
\text { extract }\end{array}$ & $\begin{array}{l}\text { Aqueous } \\
\text { extract }\end{array}$ & Ciprofloxacin \\
\hline P. aeruginosa & $9.27 \pm 0.82^{*}$ & $6.73 \pm 0.41^{* *}$ & $13.33 \pm 0.67$ \\
K. pneumonia & $10.00 \pm 0.58^{* *}$ & $7.27 \pm 0.18^{* *}$ & $14.67 \pm 0.67$ \\
S. typhi & $9.00 \pm 0.58^{*}$ & $6.27 \pm 0.48^{* *}$ & $12.00 \pm 0.58$ \\
E. coli & $12.00 \pm 0.58^{*}$ & $9.33 \pm 0.88^{* *}$ & $15.33 \pm 0.67$ \\
S. marcescens & $5.93 \pm 0.66^{* *}$ & $4.67 \pm 0.67^{* *}$ & $11.33 \pm 0.33$ \\
P. mirabilis & $8.00 \pm 0.58^{*}$ & $4.33 \pm 0.88^{* *}$ & $11.67 \pm 0.33$ \\
S. aureus & $19.07 \pm 0.64^{* *}$ & $13.33 \pm 0.44^{* *}$ & $24.00 \pm 0.12$ \\
S. citreus & $12.27 \pm 0.48^{* *}$ & $9.80 \pm 0.95^{* *}$ & $20.67 \pm 0.18$ \\
B. polymyxa & $14.00 \pm 0.58^{* *}$ & $11.00 \pm 0.58^{* *}$ & $21.87 \pm 0.47$ \\
B. cereus & $12.60 \pm 0.50^{* *}$ & $10.00 \pm 0.58^{* *}$ & $21.33 \pm 0.18$ \\
\hline
\end{tabular}

The values are the mean of three experiments \pm S.E.

${ }^{*} \mathrm{P}<0.05,{ }^{* *} \mathrm{P}<0.01$ compared to standard

agent were measured with a ruler and compared with those produced by the commercial antibiotic Ciprofloxacin.

\section{Statistical Treatments}

The results of the experiment are expressed as mean \pm SE of three replicates in each test. The data were evaluated by one-way Analysis of Variance (ANOVA) followed by Tukey's multiple pairwise comparison tests to assess the statistical significance. $\mathrm{P} \leq 0.05$ was considered as statistically significant, using software ezANOVA ver. 0.98 .

\section{RESULTS AND DISCUSSION}

Terminalia chebula is a well known plant used in ayuverdic traditional medicine for their effectiveness against wide range of diseases due to the advantage of the diversity of secondary metabolites responsible for their curing property. Despite the existence of potent antibacterial agents, the appearance of resistant or multi-resistant strains imposes the need for a permanent search and development of new drugs (Bastert, 2001).

The antibacterial activity of the crude extracts of $T$. chebula leaf gall was determined against 10 strains which include Gram-negative and Gram-positive bacteria (Table 1). The leaf gall extracts differ significantly in their activity. The ethanol extract exhibited highest antibacterial activity in terms of zone of inhibition against all the bacteria tested when compared to aqueous extract. This indicates that ethanol extract are better as compared to 
aqueous extract. These observations may be attributed to two reasons; firstly, due to the nature of biologically active components (alkaloids, flavonoids, sterols, quinine, tannins etc.) which might be enhanced in the presence of ethanol (Kabir et al., 2005). It has been documented that alkaloids, flavonoids and tannins are plants metabolites well known for their antimicrobial activity (Tschesche, 1971). Secondly, the stronger extraction capacity of ethanol could have produced a greater number of active constituents responsible for antibacterial activity. Staphylococcus aureus being the most susceptible organism, the ethanol extract could be more effective in infections related to $S$. aureus rather than other bacterial infections (Patel and Patel, 1957; Uday, 1877). Ciprofloxacin, which was used as a positive experimental control against all bacterial strains assayed, produced a good zone of inhibition, while no inhibitory effect could be observed for DMSO used as negative control.

T. chebula leaf galls have demonstrated antibacterial activity against clinical strains of selected microorganisms. The crude extract shows activity profile. As the crude extract is mixture of several constituents, it exerts better activity profile. The basis of varying degree of sensitivity of test organism is due to the intrinsic tolerance of microorganism, chemical nature and structure of the constituent for the mode of action on the control of growth of microorganism is beneficial. The plant has been used in curing various ailments in India; hence the phytoconstituents is useful to develop the molecules against infectious diseases. T. chebula leaf galls has shown the better activity profile against gram positive and gram negative bacteria especially against $S$. aureus.

\section{CONCLUSION}

The results of the investigation do not reveal which chemical compound is responsible for the aforementioned activity. Further studies are needed to isolate the exact active compound, which are responsible for the antimicrobial activity. In addition, in vivo studies are necessary to determine the toxicity of the active constituents, their side effects and diffusion in different body sites. Further research is required for the development of broad spectrum antibacterial agent of plant origin.

\section{ACKNOWLEDGEMENT}

We acknowledge Dr. R. Chenraj Jain, President, Jain University Trust., Dr. N Sundararajan, Vice Chancellor, Jain University and Prof. K.S. Shantamani, Chief Mentor, Jain University, Bangalore for their kind support and encouragement.

\section{REFERENCES}

Ahn, M. J., Kim, C.Y., Lee, J.S., Kim, T.G., Kim, S.H., Lee, C. K., Lee, B. B., Shin, G. G., Huh, H., Kim, J. (2002). Inhibition of HIV-I integrase by galloyl glucose from Terminalia chebula and flavonol glycoside gallates from Euphorbia pekinensis. Planta Medica, Volume 68, Pages 457-459. [DOI].

Ali-Shtayeh, M.S., Yaghmour, R.M., Faidi, Y.R., Salem, K., AlNuri, M.A., (1998). Antimicrobial activity of 20 plants used in folkloric medicine in the Plastenian area,Journal of Ethnopharmacology, Volume 60, Pages 265-271. [DOI].

Aneja, K.R. (2003). Experiments in Microbiology, Plant Pathology and Biotechnology (4th Ed., pp 196-197), New Delhi, India, New Age International Ltd.

Anonymous. (1999), Indian Herbal Pharmacopoeia. Regional Research Laboratory, Jammutwai and Indian Drug Manufacturers Association, Mumbai, Volume 2, Pages 51.

Bag, A., Bhattacharyya, S. K., Bharati, P., Pal, N. K, Chattopadhyay, R. R. (2009). Evaluation of antibacterial properties of Chebulic myrobalan (fruit of Terminalia chebula Retz.) extracts against methicillin resistant Staphylococcus aureus and trimethoprim-sulphamethoxazole resistant uropathogenic Escherichia coli. African Journal of Plant Science, Volume 3, Pages 25-29.

Bastert, J. (2001). Current and future approaches to antimycotic treatment in the era of resistant fungi and immunocompromised hosts. International Journal of Antimicrobial Agents, Volume 17, Pages 81-91. [DOI].

Chattopadhyay, R. R., Bhattacharyya, S. K., Medda, C., Chanda, S., Datta, S., Pal, N. K. (2007). Antibacterial activity of black myrobalan (Fruit of Terminalia chebula Retz.) against uropathogen Escherichia coli. Pharmacognosy Review, Volume 11, Pages 212-215.

Cheng, H. Y., Lin, T. C., Yu, K. H., Yang, C. M, Lin, C. C (2003). Antioxident and free radical scavenging activities of Terminalia chebula. Biological and Pharmaceutical Bulletin, Volume 26, Pages 1331-1335. [DOI].

Collins, C.H., Lyne, P.M., Grange, J.M., (1989). Microbiological Methods (6th Ed., pp 410), London, Butterworhs Co. Ltd.

Cowan, S.T. \& Steel, S. (1993). Manual for the Identification of Medica Bacteria, Barrow GI, Feltham RKA (Eds), Cambridge University Press, Pages 32. 
Gandhi, N. M. and Nayar, C. K. (2005). Radiation protection by Terminalia chebula some mechanistic aspects. Molecular and Cellular Biochemistry, Volume 48, pages 277.

Kabir, O.A., Olukayode, O., Chidi, E.O., Christopher, C.I., Kehinde, A.F. (2005). Screening of crude extracts of six medicinal plants used in South-West Nigerian unorthodox medicine for anti-methicillin resistant Staphylococcus aureus activity. BMC Complementary and Alternative Medicine, Volume 56, Pages 1-7.

Kaur, S., Arora, S., Kaur, K., Kumar, S. (2002). The in vitro antimutagenic activity of Triphala - an Indian herbal drug. Food and Chemical Toxicology, Volume 40, Pages 527-534. [DOI].

Kim, H. G., Cho, J. H., Jeong, E. Y., Lim, J. H., Lee, S.H. (2006). Growth inhibitory activity of active component of Terminalia chebula fruits against intestinal bacteria. Journal of Food Protection, Volume 69, Pages 2205-2209.

Kirtikar, K. R and Basu, B. D. (1987). Indian Meteria Media, International Book distributors, Dehradun, India, Volume 3, Pages 333-335.

Nair, R., Kalariya, T., Chanda, S. (2005). Antibacterial activity of some selected Indian medicinal flora. Turkish Journal of Biology, Volume 29, Pages 41-47.

Patel, R.P., Patel, K.C. (1957). Antibactrial activity of Cassia tora and Cassia obovata. Indian Journal of Pharmacology, Volume 19, Pages 70-75.
Roopashree, T. S., Raman Dang. Shobha Rani, R. H. and Narendra, C. (2008). Antibacterial activity of antipsoriatic herbs: Cassia tora, Momordica charantia and Calendula officinalis, International Journal of Applied Research in Natural Products, Volume 1, Issue 3, Pages 20-28.

Sabu, M. C., Kuttan, R. (2002). Anti-diabetic activity of medicinal plants and its relationship with their antioxidant property. Journal of Ethanopharmacology, Volume 81, Pages 155-160. [DOI]

Saleem, A., Husheem. M., Harkonen, P., Pihalaja. K. (2002). Inhibition of cancer cell growth by crude extract and the phenolics of Terminalia chebula Retz. fruit. Journal of Ethnopharmacology, Volume 81, Pages 327-336. [DOI]

Shantha, T. R., Shetty, J.K.P., Yoganarasinhan, S.N., Sudha, R. (1991). Farmocognostical studies on south Indian market sample of Karkatasringi- Terminalia chebula (leaf gall), Ancient science of life, Volume 11, Pages 16-22.

Tschesche, R. (1971). Advances in the chemistry of antibiotics substances from higher plants: Pharmacognosy and phytochemistry. In: Proceeding of the $1^{\text {st }}$ International Congress, Murich, 1970, Wagner H, Horharmmer L (Eds), SpringerVerlag, Berlin,; Pages 274-289.

Uday, C.D. (1877). The Materia medica of the Hindus: Compiled from Sanskrit Medical Works. Thacker, spink, Bombay, Pages 38 